\title{
An Examination of the Use of a Vocabulary Instruction Strategy (Content Acquisition Podcast) on the Vocabulary Comprehension of Students, Through the Use of Action Research Methods
}

\author{
Ashleigh Tomcics ${ }^{1}$, Oriana Long-Auman ${ }^{1}$, and Lorraine Munion ${ }^{1}$ \\ ${ }^{1}$ Susquehanna University, Selinsgrove, PA, USA \\ DOI: https://doi.org/10.47611/jsr.v10i1.794
}

\section{$\underline{\text { ABSTRACT }}$}

Academic vocabulary is a strong indicator of a student's ability to learn subject content. Subject mastery is a strong predictor of academic achievement. Academic vocabulary comprehension is a critical component of academic success that is required for making meaning of new information and demonstrating mastery of academic concepts through the construction of meaningful, articulate assessment responses. Repeated exposures to academic vocabulary and multiple opportunities to practice using academic vocabulary are likely integral to the ability to use academic texts in a meaningful way (Townsend, Filipinni, Collins, \& Biancarosa, 2012). This paper reports of an examination of the effect of the use of CAPs (Content Acquisition Podcasts) on vocabulary acquisition among two groups of students, both inclusive, both including ELL students, by two student researchers.

\section{Introduction}

As recently as ten years ago, education research indicated that approximately $70 \%$ of k-12 students may struggle with some aspect of reading or writing (Kuder, p.155, 2017). When considering students learning to read, vocabulary development is key to literacy success. "Vocabulary knowledge is an important component of being able to comprehend text and is necessary for overall academic success regardless of grade level or content area (Alves et.al, p.1, 2017)." When students struggle with reading it is often linked to their limited sight-word vocabulary, or vocabulary acquisition. Language is a way for humans to access the world but when students experience difficulty with vocabulary "they have a hard time keeping up with the course content (Alves et.al, p.1)." It is essential that teachers use explicit instruction, direct strategies, and indirect strategies when teaching vocabulary (Razali \& Razali, p..2, 2013; Alves et.al, pg. 1, 2017). "Research is clear that students need multiple exposures to a term before they internalize the meaning" (Alves et.al, p.3, 2017).

Language development plays a large role in reading comprehension as well. "Most students who struggle with reading comprehension also demonstrate weak language comprehension skills, since reading comprehension is largely dependent upon language comprehension (Wiechmann et. al, pg. 4, 2014)." As stated by Razali, "mastering vocabulary is the primary thing that every student should acquire in learning English (pg.2, 2013)." Vocabulary acquisition is fundamental for all students including ELL students and students with special needs. Vocabulary builds upon language development as well as comprehension skills and thus, vocabulary is a building block for literacy.

There are many different methods for teaching vocabulary. Younger children do not necessarily rely on vocabulary knowledge as much as sight word recognition. One method used to teach sight words is the Traditional Drill Method in which a teacher holds up a word, the target word is modeled, and the child is asked to repeat the word. The more the child is exposed to the word the more likely they are to internalize the word (January et al, pg. 2, 2016). 
"Research has also found that the inclusion of known words increases motivation, task preference, and task completion rates (Volpe, pg. 2, 2011)."

"Evidence indicates that the primary processing problem for children with learning disabilities is a phonological processing difficulty that impedes word recognition (Brennan, p.1, 2000)." Introducing sign language into the everyday sight word lessons is a way to improve retention of words. "Involving sign language in a total communication reading program has proven successful for students; teachers add a kinesthetic aspect to the lesson and putting together more of the learning modalities (Brennan \& Miller, p.1, 2000)." Other activities that can benefit in this manner are writing in the air, clapping out synonyms, and fingerspelling, which support kinesthetic learners.

For secondary students, explicit instruction, repeated exposure, and multimedia techniques are often the most effective strategies to increase vocabulary acquisition, especially when combined. Kuder (2017) tells us that "researchers found that when the students with disabilities were taught using CAPs (content acquisition podcasts), they had significantly higher scores on vocabulary probes and acquired the words faster than when they were taught using the standard approach," (p. 162).

This study is the product of an action research project conducted by two education students in a Master's level class. The primary purpose for the study was to examine the effect on content-specific vocabulary acquisition for two groups of students, as measured by pre and post-test assessment. This comparison allowed the student researchers (one of whom was also the teacher of record for her group of students, the other was the student-teacher assigned to that group of students) to determine the value of using teacher-constructed CAPs in vocabulary instruction, as part of their instructional protocols already employed by the teacher/student researcher. Each CAP was constructed using the 12 principles of multimedia learning (Mayer, 2009). Vocabulary was selected from the curriculum materials being used by the current teacher of each group of students. The two student researchers conducted their segment of study at different instructional levels; one segment being conducted in a full-day kindergarten class, which included five ELL students. The second was conducted in an eighth-grade class, however, only the ELL students participated in the research. Both classes were part of the same district, which was located in a low SES rural area in the midAtlantic region.

\section{Research question:}

Would students who use the CAP intervention more accurately retain and recall prescribed vocabulary terms as measured by a curriculum-based assessment than those students who use traditional vocabulary study methods?

\section{Methods section (kindergarten class)}

This part of the study utilizes the incorporation of teacher-constructed CAPs into the daily kindergarten reading program routine. A pre-assessment was conducted on 20 kindergarten students to assess their knowledge of the sight word vocabulary terms before CAPs were introduced to the daily routine. The CAPs each included a sight word of the day, syllabication, a sentence with correct usage of the term, writing in the air, as well as sign language representation of the term. The goal was to expose the students to the sight words as much as possible (repeatedly within the CAP, and in using distributed practice throughout the lesson) in order for them in internalize the word. Each day a word was introduced, the students were also expected to use the word in a sentence during writing practice. A postassessment was given to all students to measure their growth of sight word recognition after the CAPs installation period.

\section{Methods section (eighth grade class)}

This part of the study utilizes CAPs for a group of three ELL students in pull-out sessions outside of regular English class. The students were introduced to the unit vocabulary terms along with their class. A pre-assessment was then conducted before the integration of CAPs into the lesson activities. Each of the study participants received training on the use of the CAPs and the graphic organizer. They achieved 100\% accuracy on the use of a sample CAP and graphic 
organizer after the training. For this part of the study, each CAP included: the term and syllabication, its origin, a definition, a synonym, an explanation of the synonym, an example, a non-example, an antonym, an explanation of the antonym, a key word, and the term and syllabication one last time. Each of the three students also filled out a graphic organizer for each term while watching the CAPs. The graphic organizer required students to write the term, define it, use it correctly in a sentence, and to give an example. Students took the post-test the day after the pre-test, graphic organizer, and CAP, in order to check for retention in addition to recall.

\section{Resuts}

\begin{tabular}{|c|c|c|c|c|}
\hline \multicolumn{5}{|c|}{ Data Table 1 (Inclusive kindergarten class) } \\
\hline Group & $n$ & Mean & SD & $p$ \\
\hline Whole Class & 20 & 73 (pre) & 27.5 (pre) & 0.000251685 \\
\hline 89 (post) & \multicolumn{4}{|c|}{15.8 (post) } \\
\hline Male only & 11 & 70.45 (pre) & 32.4 (pre) & 0.006398495 \\
\hline 85.64 (post) & \multicolumn{4}{|c|}{19.4 (post) } \\
\hline Female only & 9 & 76.89 (pre) & 21 (pre) & 0.012657023 \\
\hline 93.56 (post) & \multicolumn{4}{|c|}{9.1 (post) } \\
\hline ELL & 5 & 60 (pre) & 14.81 (pre) & 0.000463 \\
\hline 85 (post) & \multicolumn{4}{|c|}{18.22 (post) } \\
\hline Non-ELL & 15 & 84 (pre) & 20.83 (pre) & 0.0133519 \\
\hline 91 (post) & \multicolumn{4}{|c|}{15.37 (post) } \\
\hline \multicolumn{5}{|c|}{ Data Table 2 (Only students who were classified as ELL, but pulled from an inclusive class for this intervention) } \\
\hline Group & $n$ & Mean & SD & $p$ \\
\hline ELL & 3 & 25 (pre) & $\mathrm{n} / \mathrm{a}$ & 0.026635 \\
\hline 43 (post) & $\mathrm{n} / \mathrm{a}$ & & & \\
\hline
\end{tabular}

\section{Conclusion}

The data was collected from two separate learning environments within the same school district. The data in Table 1 includes data from the full class, exhibited as a whole class, and in comparative sub-groups male/female, and ELL/non- 
ELL. In Data Table 2, data is collected only from one sub-group; ELL students. This group numbered only three participants, therefore the analysis of a small data set such as this should be interpreted with reservation.

Data Table 1 reflects the responses of a kindergarten class with 20 students. A $t$-test was calculated for the whole class; which examines the change in performance between pretest and posttest. A result of 0.05 or less indicates a significant reaction. The significance ( $p$ value) was calculated for the whole class at 0.000251685 , which indicates statistically significant change in student performance between pretest and posttest. Additionally, the mean and standard deviation was calculated for the whole class, and each sub-group. The whole class mean measured 73 prior to the test, which indicates a degree of familiarity with the prescribed terms before the CAPs intervention. This was expected as the reading and writing curriculums are iterative at this level. The class mean improved to 89 posttest, after the introduction of the CAP intervention. Additionally, the standard deviation was calculated for both pre- and posttest scores, and is a measure of the degree of variance in students' scores. The standard deviation was measured at 27.5 at pretest, and measured 15.8 at posttest- this indicates much less variance in student scores. Overall, students' scores improved from 73 to 89 percent- a more than 20 improvement, with significantly less variance. When ELL and nonELL sub-group $p$ scores were compared, both components of the sub-group demonstrated significantly improved vocabulary skills, as previously described in this manuscript, with the ELL students demonstrating a much greater improvement than the non-ELL students. Interestingly, while overall scores improved for the ELL students, their score variance actually increased, suggesting there might be other factors to their achievement in the area of language-based skills. Finally, male and female students scores were compared, with both subgroups demonstrating statistically significant improvement of posttest scores over pretest scores. Male students performing slightly better than females in the significance calculation, however, female students demonstrated much less variance in the scores, suggesting a more universal effect of the intervention.

Data Table 2 offers some insight on the effect of vocabulary support for ELL students in eighth grade. The study participant group included two males and one female. The small sample size limits the statistical analysis options, however, the $t$-test calculation measures significant difference between pre and posttest scores. This suggests the intervention is effective as a tool for vocabulary development for those students for whom English is a second language.

\section{Discussion (kindergarten class results)}

From the findings it is clear that the incorporation of CAPs increased student sight word recognition. For young children the ability to recognize sight words plays a key role in early reading. Sight word recognition is very difficult for young learners because the words cannot be sounded out and do not follow the "rules" of the conventional English language. Incorporating CAPs into the routine increased recognition across the curriculum. Improvement was seen during guided reading, reading practice time, and especially writing practice. The majority of students were able to recall and write the sight words that were incorporated into our CAPs routine during writing practice. They work on their own or with the teacher to write a sentence to go with their illustration. The student is required to sound out and identify sounds in words as well as known sight words.

It is also important to note that there were 5 ELL students in this classroom and after incorporating CAPs into the routine their scores have all increased significantly (see Data Table 1). Sight word recognition is especially difficult for ELL students because they do not have the background knowledge necessary to provide context for the words. For example, the word "the" is taught and for the ELL student it is simply a word with which they have no way of associating meaning. After incorporating CAPs, that word is paired with kinesthetic, spatial, and verbal examples which lead to increased recall. It has also helped the ELL students; per observational data collected, the ELL students also demonstrated an increased ability to speak more clearly, likely because English words can be difficult to hear and make sense of in oral language, but with the CAPs, now had a meaningful place in their long-term memory. Study data indicates that the use of CAPs had a positive effect on all of the students in the study; in sight word recognition and recall, but also students are able to use the words and make meaning of them. 


\section{Discussion (eighth grade class)}

The data from this study suggests that the use of CAPs to enhance vocabulary acquisition and retention for ELL students at the middle school level creates marginal improvement. All three students showed improvement on knowledge of the week's words between the pre and post tests. Though some of this may be due to repeated exposure; the usual method of vocabulary instruction for these students - two of the three study participants exhibited final vocabulary test scores (scores on the full test after the post-test) that were several points higher than their usual vocabulary test scores. The study participants voiced a preference for the inclusion of the use of CAPs in their vocabulary instruction, and suggested they would be inclined to access them outside of class, if made available to them.

Limitations in this study include the small size of the sample group, the short period of time over which this study was conducted, and fidelity to the intervention; the students in this group elected to divert from the original study protocols by completing the graphic organizer while viewing the CAP for each term. This departure from the study protocols likely had an effect on the outcomes of this segment of the study. Further research would be appropriate to help determine the efficacy of this method for this student group.

\section{Acknowledgments}

We would like to express our appreciation to Dr. Lorriane Munion for her help with this project.

\section{References}

Alves, K. D., Kennedy, M. J., Kellems, R. O., Wexler, J., Rodgers, W. J., Romig, J. E., \& Peeples, K. N. (2017). Improving Preservice Teacher Vocabulary Instruction: A Randomized Controlled Trial. Teacher Education and Special Education: The Journal of the Teacher Education Division of the Council for Exceptional Children, 41(4), 340356. doi:10.1177/0888406417727044

Brennan, K. B., \& Miller, A. D. (2000). How Many Words Can Your Students Read? Intervention in School and Clinic, 35(3), 147-150. doi:10.1177/105345120003500303

Ciullo, S., Lembke, E. S., Carlisle, A., Thomas, C. N., Goodwin, M., and Judd, L. (2016). "Implementation of Evidence-Based Literacy Practices in Middle School Response to Intervention: An Observation Study." Learning Disability Quarterly.

Drew, S. V. and Thomas, J. (2018). "Secondary Science Teachers' Implementation of CCSS and NGSS Literacy Practices: A Survey Study.” Reading and Writing.

January, S. A., Lovelace, M. E., Foster, T. E., \& Ardoin, S. P. (2016). A Comparison of Two Flashcard Interventions for Teaching Sight Words to Early Readers. Journal of Behavioral Education, 26(2), 151-168.

doi:10.1007/s10864-016-9263-2

Kelley, J. G., Lesaux, N. K., Kieffer, N. J., and Faller, S. E. (2010). "Effective Academic Vocabulary Instruction in the Urban Middle School." The Reading Teacher

Kuder, S. J. (2017). "Vocabulary Instruction for Secondary Students With Reading Disabilities: An Updated Research Review." Learning Disability Quarterly 
Lesley, M. (2011). “Understanding Resistance: Preservice Teachers' Discourse Models of Struggling Readers and School Literacy Tasks." Journal of Adolescent and Adult Literacy.

Mayer, R.E., (2009). "Multimedia Learning” Cambridge University Press, Second Edition

Meyers, S., Cydis, S., and Haria, P. (2015). “A Partnership Between Professors and Middle School Teachers to Improve Literacy Skills of Adolescents: A Pilot Study.” Reading Improvement.

O’Connor, R. E., Beach, K. D., Sanchez, V., Bocian, K. M., Roberts, S., and Chan, O. (2017). "Building Better Bridges: Teaching Adolescents Who Are Poor Readers in Eighth Grade to Comprehend History Text." Learning Disability Quarterly.

Razali, K., \& Razali, I. (2013). Strategies In Improving Reading Comprehension Through Vocabulary Acquisition. Englisia Journal, 1(1). doi:10.22373/ej.v1i1.136

Stetter, M. E. and Hughes, M. T. (2017). "Using WebQuests to Promote Reading Comprehension for Students with Learning Disabilities." International Journal of Special Education.

Volpe, R. J., Mulé, C. M., Briesch, A. M., Joseph, L. M., \& Burns, M. K. (2011). A Comparison of Two Flashcard Drill Methods Targeting Word Recognition. Journal of Behavioral Education, 20(2), 117-137. doi:10.1007/s10864011-9124-y

Wiechmann, J., Richardson, M., \& Jones, D. (2014). A program evaluation of the Language Lab ${ }^{\mathrm{TM}}$ : Response to intervention program for teaching grammar, vocabulary, and storytelling. Journal of Instructional Pedagogies, 15, 120. doi:EJ1106744 